\title{
QUASI-SUBJECT COMMODITIES - LABOUR, MINIMALISM, AND THE SOCIAL LIFE OF THINGS
}

\author{
PAUL SMITH
}

\begin{abstract}
Commodities play an integral role in the creation and maintenance of personas - to such a degree that they begin to take on characteristics of labor, provenance, and politics, such as distressed clothing or fair trade labels. This essay proposes that we have begun to freight our commodities with their own personas and imagined subjecthoods, and that this shift is foreshadowed in the transformation of artistic practices in the late twentieth century.

Two theories on the status of contemporary artworks have come to recent prominence-David Joselit's "Painting Beside Itself," which argues that artworks need image not just their status as commodities but rather their circulation and [social] networks, and Isabelle Graw's claim that artworks are being reconsidered as imaginary "quasi-subjects." Thus, artworks are being equated with persons, not by their looks but by their actions. This new apprehension of objects finds its own roots in American sculptural debates of minimalism in the late 1960's, where theorists resorted to ascribing subjectivities to objects to account for the relentless anthropomorphism of even those works which attempted to fully excise the human form.
\end{abstract}

Proponents of "quasi-subjecthood" argue from two tacks: the object either is a subject of its own, or is propped on the "ghostly presence" of its maker. I believe this indicates two predominant characterizations of commodities: full subjects, or signs of an absent maker. Both arguments flirt with a fetishism that, in giving personas and personalities to objects, threatens to erase the social conditions in which each object is made. However, there may be a way in which these imaginaries can be harnessed as prosthetics for our communities. This essay explores possible avenues for artists and critics to create ethical objects for societies of art.

\section{KEY WORDS}

Minimalism, quasi-subject, transitivity, commodity culture

\section{INTRODUCTION}

The following essay investigates some of the projections that distinguish artworks as unique among commodities, through a tracing of the ramifications of art critics both midcentury and contemporary. Three distinct projections, widely promoted in the art world, play major roles in vesting the art object with the sophisticated and semi-autonomous subjectivity of a persona. These projections are "transitivity" and "quasi-subjectivity," both with theoretical roots in the early 1960s, combined with a brief on the motor of the persona with which the artwork separates itself from other commodities and currencies: a privileged relationship to, and projection of, a very human kind of labour. With a thorough understanding of today's 
language of critique, we can explore several avenues contemporary artists have taken to sidestep or exacerbate the increasingly saleable function of social projection.

In his writing on commodity fetishism, Marx showed how relations of production were abstracted and concealed in consumer products, but today we see labor inscribed upon every communicating surface and every skin. This new commodity is a "social hieroglyph" that signals exactly who made it, how, and where. It is rough around the edges and a bit touched-looking, elaborating several ways at once of calling itself organic, fair and real... It is the old trick of the honest commodity. (Kelsey, 108)

Commodities play an integral role in building identities. Affluent consumers purchase objects that loudly wear their vintage, craft, or brand. Promoted as "lifestyle marketing" and "ethical eating," fair-trade coffee and bespoke shops promise the luxury of sustainable goods pronouncing their provenance, a "touched-look" that rubs off on the buyer. As will be seen, however, the producer in turn sheds a subjectivity onto the commodity-the organic tomato makes its history clear, promising that even as an object, it participates or acts in an unusually ethical sphere.

Artisanal coffee, beauty cream, and handbags often name the labourer who packaged, produced, or sourced them. Luxury goods promise articulation, a trick learned from the historical analysis of art objects. In High Price: Art Between the Market and Celebrity Culture, Isabelle Graw explores how "artworks can be viewed as precursors to branded goods" (High Price 128). The transparency and authorial mythos of many consumer goods take their cues from "the personalisation of brands [which] correlates with the personalisation of artworks, just as the consumer experience is based on the experience of art" (129). Luxury goods typically offer at least the semblance of use, however, and so differ from art objects that contain only prestige, class and the depth of uselessness. Graw's careful theory of the art object's "quasisubjecthood" has found broad acceptance in the art world. This is prosopopoeia at its most hyperbolic, and it shares many characteristics with another popular term in art criticism, David Joselit's "transitive painting." First named in the 2009 essay "Painting Beside Itself," transitive artworks are those-increasingly common-objects that make explicit their social, economic and geographic travel, a movement they produce seemingly at will. These lauded concerns-for "quasi-subjecthood" and network aesthetics-are also clearly seen in broader discourses around objects, such as the object "post-internet," Nicolas Bourriaud's "relational aesthetics," and Bruno Latour's "actor-network" theories.

Graw and Joselit are indebted to American art critics of the 1960's for composing a new vocabulary for the analysis of art. Faced with the increasingly abstract objects of Minimalism, theorists resorted to vesting objects with imaginary subjectivities to account for the relentless anthropomorphism of, for example, Robert Morris' 6x6x6 foot cube.

\section{Transitive PaInTING AND QUASI-SUBJECTHOOD}

In 1992, Giorgio Agamben observed an increasingly networked character of art:

[E]ven the Mona Lisa, even Las Meninas could be seen not as immovable and eternal forms, but as fragments of a gesture or as stills of a lost film wherein only they would regain their true meaning... it is as if a silent invocation calling for the liberation of image into gesture arose from the entire history of art. (Agamben, 56) 
For Agamben, language in the twentieth century became code-gestures waned and so were claimed as a property of cinema and visual art, in order to recoup what we had lost. Agamben's writings on gesture are indicative of the increasing discourse around how objects play active roles in our social lives, even assuming properties of performativity and subjecthood. This increase is reflected inamong other writings - the popularisation of Bruno Latour's Actor-network theory. Along with the rise of both relational aesthetics and the attention on Cologne's 1980's arts scene, in which artworks are primarily an impetus for socialization, networks have come to extreme prominence of late.

Interviewed by Jutta Koether in 1990-1991, Martin Kippenberger claimed "[simply] to paint a picture and hang it on the wall is dreadful! The whole network is important. Even spaghettini..." (Joselit, "Painting” 125). This rejoinder is cited by David Joselit in his influential "Painting Beside Itself," which rapidly popularised his "transitivity."

Transitive painting... invents forms and structures whose purpose is to demonstrate that once an object enters a network, it can never be fully stilled, but only subjected to different material states and speeds of circulation ranging from the geologically slow (cold storage) to the infinitely fast. ("Painting"132)

Transitive painting - perhaps todays dominant style, incorporating a range of art-critical models in its fold-images its own social, digital and economic circulation. Here Joselit's analysis holds Agamben's hand - where the painting is a still and un-reproduced image, barred from the right to circulate, its auratic gains in value are rendered nil. Transitive art, like the peripatetic denizen of today's biennial-visiting high art world, accrues value with each new sighting, siting, and citing.

Painting has always been couched in social and economic transfers. But transitive art is both the demand that objects "explicitly visualise networks" and that they actively participate in them. As Joselit says of Koether, she "actualizes the behavior of objects within networks... [with] this notion of passage" ("Painting" 128). As we are inundated with the language of networks, it is no longer sufficient, according to some critics, for an artwork to cede claims of its objecthood in favor of representation. Rather, the rigorous art object must visualise and perform its inevitable movement—objects must in some way act.

In his book After Art, Joselit elaborates the effects of network aesthetics by listing four spatially-determined categories of art criticism. Meaning lies "behind the object," "beside the object," "within the object," and "before the object"—respectively, iconographic symbols, social histories, indexical or semiotic analysis and "active" meaning (Joselit, After Art 43-45). Joselit promotes the 'before the object' mode of meaning, which he argues stems from "the movement of the object... Meaning moves with the artwork" ("States"). Appropriation, avatars, and platforms (the "liberation of institutional movement" ("States")) are named as prime conductors of this meaning-by-motion. Contemporary art criticism defines meaning as what travels with the artwork and exists only in travel.

Talking about her work in Spike Art Quarterly 22: Painting as Code, Rachel Rose says a painting becomes "almost like a body of its own." Seen as bodies, artworks exchange themselves and argue much as we do. They are paid for, not paid. Graw's theories position artworks (particularly paintings) as fetishes of actants, things that perform and determine, what she calls "quasi-persons." Graw explains that painting is "particularly disposed to support the expectation-widespread in the art world - that acquiring a work of art means getting a hold on the artist's labor capacity and therefore owning a slice of her life" ("Thinking" 46-47). The deftness of this analysis is its unspoken refutation of art's medium-specificity as materiallybased. Rather, Graw leverages public imaginaries to make her point: art objects are only special because people believe they are, a claim shored up by recurring privilege in critical discourse and price points. Increasingly, financial and idea economies are at the forefront of capitalising 
subjectivities —alternately termed "spirit," "human capital" or "semiocapitalism" - it would appear that art is particularly disposed to supply this demand.

Artworks facilitate this by a twofold relationship to subjecthood: on the one hand (and particularly, Graw claims, in painting), "we are still dealing with the ghost of a presence" ("Thinking" 50). Here the indexicality of artworks-their ability to suggest the latent presence of an absent maker-provides their ability to speak. When we talk about art, we often elide the object, referring to "a Warhol" or "a Morris," as though products are their producers. This ability for artwork to encapsulate the artist's subjectivity appears to allow it a measure of independence from the artist. Graw acknowledges this tendency-and carefully avoids fetishism - when she states that even "those antisubjective procedures that aim at undermining authorship in painting end up granting subjectivity to it. These works seem to have a life of their own and appear to be self-active, as if they painted themselves" (Dusseldorf 40).

Freighting painting with a subjecthood of its own is not only a means to facilitate the sale or transmission of the artwork: this is also the mechanism that allows us to aver that an artwork "critiques something" - a claim central to art's activist impulses. However, like Graw, "the idea that an artwork would articulate a critique seems to me, in any event, to be questionable" (Graw, Adorno 24). Artworks appear to be independent ("I am interested in painting's capacity to trigger vitalist projections" (Graw, Dusseldorf 40), while depending on a spectral link to the artist.

Graw claims an artwork reaches a pinnacle of price based on "the assumption that it is priceless" (High Price 29) — such that art objects are mortgaged to what is presumed an unplumbable depth of history, culture, or character-much like subjectivities. Through the stickiness of the artist's subjectivity, this latent persona, to the object, this thing is equated with a similar type of subjective summit or unknowability as resides in the mind of the artist. Even in those cases where the artist mobilizes industrial, anti-expressionistic techniques, the art object, through a gesture of placement as an artwork, retains the capacities of its (still fetishised) maker. As Diedrich Diederichsen argues, "the aura of the original [even in cases of artistic multiples and highly distributable works] causes the living artistic labor to appear as a patina" (42). If typical commodity fetishism is the activation of imagined socialities situated in the past that obfuscate the producer, the specifically artistic commodity fetishism instead relies on imagined socialities projected into the future of the producer. Socialities imagined, that is, only to a degree, as artists must always be able to reiterate or re-supply their "authentic" lives to buttress value of their work.

If the power of an artwork is its "charge," as David Joselit says, it can only achieve circulation and buzz by surviving radical decontextualization from its author. Though the aura of authority is ever-present, the artwork still needs to be self-sustaining. Decontextualizationor estrangement-of a work from its author allows it a life "of its own," not unlike the financial life of most artworks post-sale (excepting the following price increase for the rest of an oeuvre). Although the artist's subjectivity is sticky, it need not be materialized forever. Things travel better without baggage. The artist must be eminently summonable-the emergency credit card-but not actively present in the artwork's day job.

Because their job is movement, contemplation, being seen, or just being, artworks, unlike other commodities, must continually prove their value with recourse to their pricelessness and what Diederichsen calls a "second order use-value". This is the use-value of being everything but applicably useful in a circulation or an attention economy by vacillating between filiality and waifishness. It is "both a special kind of commodity and the prototypical commodity at the same time" Graw observes (High Price, 130), for artworks always claim to be 
unquantifiable, full of meaning. This relentless exceptionality is similar to the exceptional states of subjects among things even as they sell their labour, just as the thing sells its service. The transcendental quality - attributed in secular society only to individuals and individual artworks-makes us desire to be artworks. When Graw says "the art market relies on a belief in the remoteness of its products from the market [,] it is obliged to emphasize this autonomy for the simple reason that it forms the basis of the product's marketability" (High Price 138), we could say the same for our belief that we are more than our ever-present labour.

In his essay "In Praise of Actuality" Hal Foster diagnoses the proliferation of performative models of making, presenting, and writing about work as tender to an increased desire for the blatant appearance of the qualities of subjectivity. Foster writes, "the performative does not actualize... so much as it virtualizes. It seems to offer the presence we desire, but it is a spectral presence, one that famishes, with the result that as viewers we come to feel a little spectral as well" (Bad New Days, 130). Perhaps the tendency for a performative or process-based reading of artworks (and the implication of these qualities onto the object absent of a maker) is indicative of the increasing abstraction with which we perceive our subjecthoods. It could also point to a substitutability of presence and performance whereby, in a world Foster laments as "Post-Critical," labour and currency are fluid enough to be present enough only when in appearance. In his own take on anthropomorphism, Foster states:

[I]n capitalist modernity, subject-object relations are overridden by the commodity form, which tends to refashion the image-object as an agent-person in its own terms. Any attempt to animate the artwork in another way must confront the sheer force of that pervasive spell... the apparent liveliness in things should not be confused with the actual liveliness of people, thoroughly imbricated though the two often are in the present. (Bad New Days 121)

It may help to understand why the art object is simultaneously an exception to the general laws of commodities and yet wholly paves their way by taking stock, briefly, of what artworks can be exchanged for, and appear to act as: autonomous subjects capable of activity; speculative currency; the body (and all substitutions) of the performer/artist. No other commodity but that one identified with and otherwise only with humans-our labour as humans-is this fluid. Thus Foster might overstep the assumed powers of the "autonomously" labeled artwork when he claims that his critique is "motivated by a resistance to any operation whereby human constructs are projected above us and granted an agency of their own, from which position and with which power they are more likely to overbear us than to enlighten us" (Bad New Days 121). If the most rudimentary social histories have taught us anything, it is that, outside the commodity form at least, autonomy and individual agency on a generally-human scale grant oppression quicker than power. If the artwork has fallen from its transcendental pedestal, maybe calling it a person, too, is a way of limiting its strength.

Perhaps this dependence on the absent maker is why Joselit allows the object the rights to perform like a subject but falls short of naming it one. Transitive paintings might travel like their authors as though we imagine their partially-autonomous presence to be that of the painter. This formulation allows us to reconcile painting's quasi-subjecthood with its author's quasi-presence. The indicative mark of subjecthood cannot be discarded, only moved between artwork and artist. Even if it can seemingly move at will (a seeming that creates value), when subjected to analysis painting certainly cannot mean on its own.

Twentieth century animism is carefully traced in Brown's Thing Theory. Brown cites Frank O'Hara's lines that “the eagerness of objects to/be what we are afraid to do//cannot help but move us" (Brown, 14). There can be exemplary ramifications for quasi-subjecthood: 
"[Adorno's] point is that accepting the otherness of things is the condition for accepting otherness as such" (Brown, 12). Nor is Joselit's transitivity the first case of a commodity finding value in and through exchange. Joselit's commodities, as artworks, find meaning through itmeaning being a primary use-value in art. In a classically Marxian analysis, value is bestowed on commodities by movement. Introducing The Social Life of Things with "commodities and the politics of value," Arjun Appadurai notes that "a commodity is any thing intended for exchange," and "value is embodied in commodities that are exchanged" (Appadurai, 9, 3). This-admittedly basic-definition of the commodity sheds light on how transitive artworks seek to visualise the creation of value. Some do so by becoming "quasi-subjects" and inventing socialities-an operation only possible by mimicking the smallest measure of life: the capacity for both labour and uselessness. Even Marx, while analysing the situation of an imaginary sociality between ordinary commodities themselves, could not escape granting subjecthood to things, once those things performed. This is evidenced by prosopopoeic play in Capital. Marx must, it seems, resort to giving commodities voice to perform his defetishistic critique. Illusion can only be performed in tandem with capitulation: "if commodities could speak, they would say this: our use-value may interest men but it does not belong to us as objects. What does belong to objects, however is our value. Our own intercourse as commodities proves it. We relate to each other merely as exchange values" (qtd in Ngai, 61-62). As Barbara Johnson claims, Marx's little screenplay is "a sign that the very thing [Marx] is arguing for is too strong for him" (qtd in Ngai, 62). Commodities always wear the social conditions of the time, and perhaps a brief tracing of the appearance of contemporary labour can illuminate dominant projections on the skins of things.

John Kelsey's "new commodities" may be the most recognisable condensations of our means of labour. Organic tomatoes, distressed clothes, bespoke shirts acutely articulate the labour behind their production. What they say matters less than the volume of their voices. Kayla Anderson notes, "a desire for communicable commodities," testified to by "the wealth of writing on evocative and talkative objects" (98). While Svenja Bromberg identifies a "turn towards objects" and the "real explosion in art exhibitions that explicitly centre around objects and articulate a relation to the philosophical strand of Object-Oriented Ontology (000)/Speculative Realism." I believe that our desire for these chatty things is correlative to our own desire to be engaging, evocative and hyper-social. As noted by Luc Boltanski, Eve Chiapello, Christian Marazzi and others, Western economies are making communication increasingly salable. Paolo Virno suggests an out in "idle talk," for perhaps the only alternative to the compulsion to speak is not silence but waste. Christian Marazzi explains "as is the case today, money and language actually overlap" (42). "We can speak of money as a form of linguistic value" (Marazzi 25). Money and language have always shared beds, but today they are inseparable. On a similar note, Kolja Reichert argues that, provisionally at least, art is a better means of exchange than money. "Art is becoming a currency, harder than coltan and gold" (Reichert). While less fluid than currency proper, art attracts in a way cash only dreams of. Appropriating Joselit's "image power," Reichert makes the case that what is truly valuable is that which has a special charge to or from visibility-and art has been long prepared for today's economy premised on attention, recognition, hits and transitivity. No other kind of commodity is better attuned to speak well and look good, with charismatic self-sales.

Even as luxury goods, according to Joshua Simon, imply a lifespan that far surpasses our own, they and other non-art commodities continue to foster a belief in possession-that we could possess a thing and turn it to our labour, the shade, ever-present, of use-value $(24-29,31)$. The commodity lives in labour. But the art object seems to offer only the most fleeting hold on its body: in many respects, it is the labour-time of the artwork which we purchase. Just as the commodity form has naturalized the permeation of labour and life for centuries, (first by implying that we are what we $d o$, and more recently that we do what we are), so it makes us 
subjects of the time we sell. Whether acting as speculative investments or discursive objects, artworks are paid for the fruits of communicative labour in time. If a central facet of the art object is human-type-labour, the artwork implies as well the salability of its unplumbable depths. If the labourer in twenty-first century America puts their affects on both display and the line, the notion of a self-to-be-sold has shifted from merely time, to whatever entrepreneurial feelings and communicative tics can be harnessed. Quasi-subjectivity thus appears as more than the appearance of autonomous travel, the spectre of the artist, or the ability to verb: behind all of these activities lies the interiority of the artwork, a shadow first fully realized, I argue, in the critical response to mid-century American Minimalism.

\section{Minimalism, ABSTRACTION, AND THE SUBJECTIVITY OF THINGS}

As American sculptors explored increasingly nonrepresentational strategies in the midtwentieth century, artworks were endowed with a new kind of power. As David Getsy notes, "anthropomorphism became a central term of derision from all sides" (9). But try as it might, freestanding sculpture could never banish the body entirely: "even the most abstract objects could not escape the analogies to human bodies" (12). To account for this relentless resemblance to the human form even in the face of the complete evacuation of figural images, art critics and historians had recourse to an imaginary subjectivity within the artwork, a tool in their vocabulary since Hegel's claim that painting is the medium "the principle of subjectivity" inhabits (Graw, Art and Subjecthood 15). Critics such as Michael Fried and Gregory Battcock began to focus on how artworks act, not what they look like. This turn from representational criticism to performative apprehension gave the objects in question the ability to perform human-like activities without human-like forms. Hal Foster argues that Minimalist sculptures "reject the anthropomorphic basis" by foregrounding seriality-an anthropomorphism classical abstraction alone could only sublate. In Minimalism,

serial production [is] made consistently integral to the technical production of the work of art. More than any mundane content, this integration makes such art 'signify in the same mode as objects in their everydayness, that is, in their latent systematic [sic]'. (Foster, The Return of the Real, 63)

When objects shed representation, we begin to apprehend them as people in their own right.

We can find one key to this rethinking of sculptural personality in Michael Fried's famous diatribe "Art and Objecthood." This essay tends to be cited as a thorough explication of Minimalism's key concerns, agreeable on most points but for Fried's tone and general distain. Fried criticises Minimalist art as "theatrical" for its evocation of presence, a presence that is not immediate or, we could say, exclusively in the present. Fried prefers those modernist experiences in which "every moment the work itself is wholly manifest... [work] that one experiences as a kind of instantaneousness" (166-7). Turning viscously on Minimalism, Fried asserts that a Minimalist "preoccupation with time-more precisely, with the duration of the experience-is, I suggest paradigmatically theatrical, as though theatre confronts the beholder, and thereby isolates him, with the endlessness not just of objecthood but of time" (166). Like people, Minimalist sculptures are durational and eschew an instantaneous read. Discovering that Robert Morris' cubes are not quite cubes, or that his optical illusions hide familiar forms, takes time. They are not immediately epiphanic.

People cannot be apprehended immediately because they harbour thoughts, feelings, or souls that their surface conceals. Before lambasting sculptural duration, Fried attacks a perceived interiority in Minimalist sculpture: "the apparent hollowness of most literalist workthe quality of having an inside-is almost blatantly anthropomorphic... as though the work in 
question has an inner, secret life" (Fried, 156). Fried does not object to anthropomorphism, but a theatrical mode of its evocation he finds in Minimalism, or perhaps anthropomorphism is acceptable only when obviously projected. Unlike nonthreatening resemblance, theatrical sculptures confront us by performing like people, as if on a stage. Fried also charges theatricality with overt objecthood: not that Minimalist works are too much like things but that they are too much like situations. People, too, step out of objecthood as durational situations that cannot be dealt with simply. One wonders if, while critiquing Minimalism's "inner, secret life," Fried knew the conditions for Morris' first Minimalist show. Tellingly, this exhibition was held not in a gallery or museum, but in a theatre. A hollow grey $2 \times 2 \times 8$ foot column (titled Column) stood on the otherwise empty stage for three and a half minutes. The column then fell to the floor, where it laid for another three and a half minutes before the stage lights dimmed. Morris operated this performance by way of a string trailing offstage, but his original plan was to fall over while standing inside the work. Unfortunately, this strategy injured Morris during rehearsal, as though comeuppance for usurping the object's autonomy. As Maurice Berger observes, "the action of the sculpture as a kind of confrontational performer created an explicit analogy between itself and the artist's body" (Berger, 48). Explicit as well is the position of the object as subject-an active being existing in time, and perhaps subject to fatigue.

Sexiness, too, is part performance. For Berger, Morris' Minimalism effects a desublimation of the erotic, long repressed by modernist sculpture and criticism's "purity and aloofness" (Ibid., 57). Nonrepresentational objects do not have a long history of being fetishised (though one might argue that representation becomes moot as the object is fundamentally altered through fetishisation). If Minimalism's forms are amatory it is because their bedrock, like that of the erotic, is the hidden, suggested or extrapolated body.

By refusing representation Minimalist eroticism comes, as it does for people, through situation, time, performance and secrecy. It is pertinent to ask what sort of confrontation Minimalist objects demand-what attention they seek. Deviations from cubes, for example in Minimalist work, tends the viewer's quick attention span. If, as Larry Johnson says, "the attention span the reader/viewer has for the work of art [is equal], say, to that of a daily horoscope or a beauty tip," (Johnson, 94), visitors to a gallery should be seen as cruising the works on display for the one that piques interest-a time-and-attention economy. Minimalist sculptures feel like people-easily "read," but generously yielding upon inspection. Ridding themselves of representation, Minimalist sculptures invite a cruising, quick eye for interest. Cruising results in the intimacy of two bodies and, in a way, little more: two presences touch while remaining distinct. Balancing interiority and recognizable form, Minimalist sculptures are cruisable objects and upon duration become subjects. In her later writings on Minimalism, Yvonne Rainer argues that Minimalist sculpture censored drama at inverse proportions to the drama in the Minimalist artist's life. In her memoir Feelings are Facts, Rainer says, "Bob [Morris] would later tell me that Barbara Rose asked him 'where were you when I was giving birth to your child? After all, I did it for you.' At which he said, he hit her across the face. As it turned out, he was with me in Maine." Rainer remembers those two weeks in Maine as "impossibly idyllic." Call it censorship or repression: either term would clearly indicate that the lack of explicit sexuality in Minimalist sculpture simply hides, or perhaps produces, a font of intrigue elsewhere. Perhaps Minimalists meant to swap feelings for facts. It is only by the disappearance of the overtly lewd that an object can acquire sexuality of near-human proportions. However, this erotic read, though promoted by many in the Minimalist milieu, found sparing acceptance in viewers: "abstract eroticism was a difficult concept for people to accept" (Berger, 58). One wonders if the confrontation, time, presence, distance and crowding, which repulsed Fried, could be the white cube when theatrically sexed. For many, Minimalist forms evoked architecture instead: Benjamin Buchloh charged one of Minimalism's faults its "failure to place 
that [viewing subject, object subject] outside the parameters of corporate decor," explains Tom McDonough (McDonough, 86-87). Can we speak of corporate sexiness? The fetishised greyflannel suit? Did Minimalism do enough to let the object-turned-subject take a sick day? Perhaps the aforementioned seriality, which undercuts representation, ushers in the spectre of the office (a latter-day take on the factory). Though Minimalism resists corporatism by rejecting flawless methods of repetition, Foster observes that its seriality is nonetheless "indicative of advancedcapitalist production and consumption, for both [Minimalism and Pop] register the penetration of industrial modes into spheres (art leisure, sport) that were once removed from them" (The Return of the Real, 66).

Three facets coincide for these critics: personhood, eroticism, and corporate interiors. By the 1960's, capitalism had carefully integrated labour and life-the "aesthetics of administration" Benjamin Buchloh would later observe in early conceptual art were forms already deeply rooted in the leisure and private lives of Americans. Minimalist works mimicked the subjects of their time: erotic and serial, with increasingly few options (the logic of serialism is quiet uniqueness). Minimalist sculptures worked small distinctions into a field of similarity, much like the office worker was compartmentalized into ever-smaller personalizations of space. Minimalism's sexiness and Minimalism's corporateness should not be seen as contradictory or as reversions of art back into object, but as realisations that artworks could perform [under] the same conditions humans do.

For Fried, the experience of works by Tony Smith or Robert Morris is one of "being distanced, or crowded, by the silent presence of another person" (Fried, 155). As Hal Foster observes,

minimalism does announce a new interest in the body-again, not in the form of an anthropomorphic image or in the suggestion of an illusionistic space of consciousness, but rather in the presence of its objects... as they often are (as Fried saw) just like people. (The Return of the Real, 43)

Interviewed about his work, Tony Smith quipped "I was not making an object" (quoted in Fried, 156). Writing on Fried's "Art and Objecthood," Isabelle Graw argues that "objecthood revealed itself to be subjecthood" (Graw, Art and Subjecthood 11). The sculptures do not resemble subjects, they act as subjects_-just as Minimalist objects are often just like people.

David Getsy proposes that the heights of nonrepresentation expanded the possibilities for sculptural meaning. Getsy observes "abstraction offers a position from which to reconsider or to visualise anew the body and personhood" (278). Perhaps this expansion resulted, at least in part, in a neo-animist vesting of subjectivity in objects-now popular in a wide range of disciplines. Minimalist critics supplied a preliminary vocabulary for artists making objects people too or, as Hito Steyerl says of images, "a thing like you and me" (46-57).

Introducing the influential book Minimal Art: A Critical Anthology, Gregory Battcock presciently observes that "what is most important is what an artist does, rather than what he is, what the object does-in terms of response-rather than what it is" (Minimal Art 36). This preference of the performing or active artwork takes a larger role in Battcock's writings as his work progressed. Five years later, in 1973, Battcock published the essay "Aesthetics And/Or Transportation" in Arts Magazine. True to the essay's title, Battcock outlines a future in which aesthetic experience is absorbed by transportation, which he predicts is, as transportation was understood in the 1970's, reaching a dim obsolesce: "artistic energies will be absorbed outside of art. One area for such aesthetic speculation is transportation," and "transportation itself will cease to be essential, as all significant transportation will involve non-physical phenomena" ("Aesthetics" 33-35). This is only half-true today, for as the internet appears to shrink and still 
the world, tourism has been steadily climbing for several decades and shipping and logistics still comprise a large role in major economies. Nevertheless, this is Battcock at his most hopeful: that the full integration of art and life will result in a finer life (whereas the opposite, considering the continued rise in airline passengers and degradation of services onboard, might be true instead). Battcock promotes "not getting anybody anyplace at all" (35).

For Battcock, the often-overlooked qualities of transportation permeate all objects. This is made clear in his 1970-71 essay "Wall Paintings and the Wall," a careful historical study of the backside of paintings. For Battcock, the development of painting as a form lies in its specific situation as a potentially mobile object in space:

\section{Painting [differs] from these other flat visual forms in that painting has a front and a back... one difference between a "painting" in the modern sense, and fresco or mosaic picture, is that there is a space between the painting and the requisite wall" ("Wall" 24-26).}

Painting's mobility was reproblematised in the 1960's, as Battcock lists a number of painters who in various ways explore painting's third dimensions (and later drafts an exhibition proposal of these artists) (26). Battcock is also sure to note that Frank Stella's shaped canvases (vital to Minimalism's evolution) are deeply indebted to early Sienese paintings: "A crucifix is flat and in the shape of a cross. A primitive Sienese painting of a crucifixion is also flat and possesses the shape of a cross" (24). Like most paintings since, these crucifixes were painted on the front and left blank on the back. However, they were designed to be relatively immobile and often to stand free from the wall-as opposed to what might be termed non-transitive paintings, which obscure their support (as though a commodity hides its true history by inventing an essence, in this case flatness).

Battcock loosely predicts a transitive art. Though wrong in particulars, the observation that aesthetics and transportation would become more intimate seems prophetic in light of today's travel-minded art elite, dubbed “itinerant artists” by Miwon Known. Kwon's suggestion that artists are transposable-providing a set of services rather than discrete objects-mirrors the idea that these same objects are also transposable service-providers. The presence of the artist ensures the success of the work, even if it is a latent presence that goes on to produce the illusion of an autonomous, active artwork. One example of this is the frequent reversion to verbs when discussing art, suggesting an artwork "questions" or "gestures." It is the object as often as the artist who performs these actions. One could say that Richard Serra's 1967-68 Verb List (to roll, to crease, to fold, to store, etc.) is projected into the artwork. Perhaps he should have included "to critique."

Battcock's writings on transportation are indebted to Mail art no less than Minimalism. However, they are prescient—and active-for Minimalism no less than Mail art. It was in Minimalism that the artwork first became a person, and the spectre of its travel appeared. Not simply a seen movement from studio to gallery, but the ability of Minimalist forms to inhabit or mask themselves in everyday shapes and assumptions lends these objects their place as genesis of both today's transitive artwork-where meaning moves with-and the exacerbated personas of artworks, appearing ever more like people, saturated with performance and their "lived" labour.

\section{BEYOND FAIR TRADE: THE HYPERBOLIC OBJECT}

What would a hyperbolic art look like? One option is talking nonstop, to exacerbate the messiness of where personas begin and end. John Kelsey advocates for such an approach in essays such as "The Self-Employment Rate" and "Escape from Discussion Island," which consists 
of "pushing discourse to its own outside, producing breaks and flights within the discursive situation in such a way that work becomes a foreign activity" (Kelsey, 98). If our nonstop chatter will be economised no matter what, endless production lets us inhabit speech without particular regard for the persons it produces. This method apprehends the (written) object as integral to the author's subjectivity, and seeks to destabilise the speaking subject by making all of the authors' works refractions of an impossibly quagmired self. Trisha Low explores this option with particular sharpness in projects such as Confessions [of a variety] and The Compleat Purge. Identifying contemporary subjectivity in a web of confessional cultures-promoted by relentless memoirs, reality tv programs and interviews-Low abolishes persona's ability to dictate or hold onto a subject by talking too much. By the end of her texts, there is no "authentic" Low left. Acceleration of sentiment and sediment play to the instability already inhabiting the confessional-each new production must dig deeper and thus eliminate all previous works (much like the classic model of avant-garde fine art).

If each confession requires abolition by a truer one, each "new commodity" mentioned previously must be supplanted by a more transparent object. Nonstop production of personas might be a viable strategy for writing, but what about the art object, which has a completely different relationship to its author? One take-possibly more cynical-is the practice of Merlin Carpenter. For most people, never working and always working create a similar bricolaged lifestyle. For two years, Carpenter had seven nights of work. Most of the time, "Carpenter thought of himself as 'on strike'" (Busta). Can a painting come to blows, strike a deal, pull its own weight? During this period, 2007-2009, Carpenter held seven shows (all titled a variation on The Opening) across Western Europe and the USA. With luxurious but blank canvases hanged on the walls, Carpenter made his marks mid-opening, splashing a handful of blank paint and a few lines of text on the waiting white monochromes. Words were ripped from the opening night crowd, evincing a low budget of premeditation. "It soon became apparent that it wasn't so much the canvases, but his guests and gallerists - the social body in attendance-that he saw as readymade" (Busta). Carpenter's casual tone erased any possibility of these events being an authentic-and-authorial action painting spectacle. Rather, Carpenter offered his viewers little more than the usual event of an opening with nothing to open. After all, "people go to art openings...because, more than the art, the occasion itself offers them the valuable prospect of increased social connectivity and the enrichment of whatever it is they personally produce. An opening is a group fantasy."

Carpenter's The Opening paintings do not just rely on a social body or slick situation: they are completely inextricable from it. As Caroline Busta observes, these paintings have only "the bare minimum for the canvases to hold indexical value." The paintings can barely support their author, and can barely live on their own without the event of the opening to confer value. Carpenter's pieces shrug off the saleable persona, suggesting that the objects [produced] are not things of agency or much less subjectivity. Rather, the art is a symptom of the people. Both art and money are situated here exclusively in the social: the "group fantasy" of openings is making some kind of capital, and Carpenter deigned to show us how pauce it really is. The Opening works might be painting beside itself at its most hyperbolic: painting beside people. Paintings that disregard our desire to make them the chattiest things demand some level of autonomy, not only because they are positioned as the centre of an event, but also because they do not work as interior design: these paintings could hardly be said to provide a better atmosphere than what they were already surrounded by.

While Minimalism gives us the confrontational object-turned-subject, Carpenter gives the confrontation almost without object. Assuming that successful paintings do, as asserted above, attain quasi-subjecthood, Carpenter presents the weakest of possible subjects. Here is an 
object we always have to make, but that is definitively an object and not a situation. Avoiding the reifying traps of latter-day Relational Aesthetics and "Zombie Abstraction" (vapid processoriented and historically-referencing canvas washes), Carpenter cuts down and shows up the art object as the projected subjects of our desires, while pulling the networks that still them to shreds.

While contemporary commodities are valued to the extent that they "express" an underlying labour, artworks are expected not only to express a labour, but also to perform (to critique, to activate, to predict, c.f. Richard Serra) it. Carpenter implies artworks that fail to locate an author, fail to locate locution, but appear as aggressively independent. They take on the characteristics of Carpenter's anti-social performance, but are more capable of clearing the room. Similarly, Trisha Low makes herself unlocatable, foiling her speech in advance. These strategies are markedly different from the prevailing tendencies of personas in art-in general, the creation of alter egos has accelerated over the past twenty years. Dozens of pseudonyms spring to mind: Reena Spaulings, Claire Fontaine, John Dogg, Donelle Woolford, to name just a few of the higher profiles. Artistic personas and pen names sell-they are flexible, wearable, and buyable, loosely associated with a history of anonymity and alter egos in avant-garde circles. As the selves-digital or otherwise-we publicise are organised by economic benefits (blanketed as convivial or professional friendships), we become more social, chatty, and self-promotional. These traits are projected onto commodities, which take greater leave of their histories and makers as they come to, almost autonomously, promote agendas, speaking with all the voices of people. While the chatty commodity has the same spectre of autonomy Marx analysed a century and a half ago, the artwork uses these conditions to much more explicit benefit. While the object appears to exist autonomously, only the artwork appears to live as such. A broken object, while devalued, has yet a shred of use-value. Broken artworks are worthless (although usually held in collections owned by insurance companies-as proofs for payment), for them labour, the labour of their activities, connections, and transitivity, has ceased.

As demonstrated, the "quasi-subjectivity" and "transitivity" we give to objects-letting them act like us-are indebted to the struggles of Minimalist critics to apprehend new breeds of objects. The sixties saw not only the rise of personhood in art, but also the beginnings of our language-based economy in which the domestic service sector rose at the expense of other means of employment. Artists are an easy fit for a labour market premised on movement, speech, and service. The fall of divisions between object and subject at least partially mirrors the failure to separate work and life-a twisted realisation of avant-garde dreams of life-art integration.

As art's quasi-subject strategies have infiltrated mass consumer goods (just as the spectre of "luxury" is sold to a wider and wider public), what options do we have for ensuring our commodities are ethical if ethics is not synonymous with transparency? The trick might be accepting the reification of the author and the object (both together and separately), but confusing the relations between the two to such a degree that neither can be thought of as autonomous. In the work of Merlin Carpenter, arts' social pretension is in full force and, as such, begins to act as social prosthetic. Carpenter, in a turn rare for contemporary artists, upset the usually smooth schmoozing of an art opening by giving us the subjects we crave, but too weak to live without us.

For Getsy, Minimalist abstraction "proposed unforeclosed accounts of 'what a person is" (Getsy, 276). Abstraction's refusal to transpose imagery (or representation) into capital might still hold these utopic qualities, but we must ask how sociality itself is abstracted by works. The expansion of personhood in the 1960s freed othered bodies to be accepted as bodies, but also 
created devious commodities-physical precursors to bots. The next "new commodity," actively ethical and exemplifying quasi-subjectivity, must choose to be cacophonous-so we can forget it.

\section{WORKS CITED}

Agamben, Giorgio. Means Without End: Notes on Politics. Trans. Vincenzo Binetti and Cesare Casarino. Minneapolis, London: University of Minnesota Press, 2000. 54-55. Print.

Anderson, Kayla. Art Beyond Anthropocentrism: Models for an Object-Oriented Worldview. Diss. The School of the Art Institute of Chicago: Department of Visual and Critical Studies, 2014. 98. Print.

Appadurai, Arjun. "Introduction: commodities and the politics of value." The Social Life of Things. Ed. Appadurai. New York: Cambridge University Press, 1986. 3-9. Print.

Battcock, Gregory. "Aesthetics And/Or Transportation." Arts Magazine, September/October 1973. 33-35. Print.

---"Introduction." Minimal Art: A Critical Anthology. Ed. Gregory Battcock. New York: E.P. Dutton \& Co., Inc.,1968. 19-36. Print.

---“Wall Paintings and the Wall.” Arts Magazine 45.3 (December 1970-January 1971). 24-26. Print.

Berger, Maurice. Labyrinths: Robert Morris, Minimalism, and the 1960s. New York: Icon Editions, 1989. 48. Print.

Bromberg, Svenja. "The Anti-Political Aesthetics of Objects and Worlds Beyond," Mute, July 2013. Accessed January 20, 2015. Web.

Brown, Bill. "Thing Theory." Critical Inquiry 28, no. 1, (Autumn 2001). Chicago and London: University of Chicago Press. 1-22. Print.

Busta, Caroline. The Opening. Berlin: Sternberg Press, 2011. No page numbers. Print.

Diederichsen, Diedrich. On (Surplus) Value in Art. Trans. James Gussen. Berlin: Sternberg Press, 2008. Print.

Foster, Hal. Bad New Days: Art, Criticism, Emergency. London, New York: Verso, 2015. 120-130. Print.

--- The Return of the Real. Cambridge, MA; London, England: October Books, Massachusetts Institute of Technology, 1996. 38-63. Print.

Fried, Michael. "Art and Objecthood." In Art and Objecthood: Essays and Reviews. Chicago and London: University of Chicago Press, 1998. 148-172. Print.

Getsy, David. Abstract Bodies: Sixties Sculpture in the Expanded Field of Gender. New Haven: Yale University Press, 2015. 9-12, 128-130. Print.

Graw, Isabelle. Adorno: The Possibility of the Impossible. Trans. James Gussen. New York, Berlin: Lukas \& Sternberg, 2003. 24. Print.

--- "Introduction" in Art and Subjecthood: The Return of the Human Figure in Semiocapitalism. Eds. Isabelle Graw, Daniel Birnbaum, Nikolaus Hirsch. Berlin: Sternberg Press, 2011. 17. Print.

--- High Price: Art Between the Market and Celebrity Culture. Trans. Nicholas Grindell. Berlin: Sternberg Press, 2009. Print.

---"Our Love for Painting: a Conversation between Charline von Heyl and Isabelle Graw." In Dusseldorf: Paintings from the early 90's. New York: Petzel Gallery, 2015. 40. Print.

---“The Value of Painting: Notes on Unspecificity, Indexicality, and Highly Valuable QuasiPersons" in Thinking Through Painting: Reflexivity and Agency Beyond the Canvas. Eds. Isabelle Graw, Daniel Birnbaum, Nikolaus Hirsch. Trans. Emile Florenkowsky. Berlin: Sternberg Press, 2012. 46-47. Print.

Johnson, Larry, interviewed by David Rimanelli. "Highlights of Concentrated Camp." Larry Johnson. Munich, New York, and London: Prestel Publishing, 2009. 94. Print. 
Joselit, David. "Painting Beside Itself." October 130, Fall 2009. Cambridge, MA; London, England: Massachusetts Institute of Technology. 125-132. Print.

--- After Art. Princeton and Oxford: Princeton University Press, 2013. Print.

Kelsey, John. Rich Texts: Selected Writing for Art. Daniel Birnbaum and Isabelle Graw, eds. 2nd. Berlin: Sternberg Press, 2012. Print.

Marazzi, Christian. The Linguistic Nature of Money and Finance. Trans. Isabella Bertoletti, James Casciato and Andrea Casson. Los Angeles: Semiotext(e), 2014. Print.

McDonough, Tom. "'A certain relation to reality': Isa Genzken between subject and object." I'm Isa Genzken, the Only Female Fool. Berlin: Sternberg Press, 2014. 86-87.

Ngai, Sianne. Our Aesthetic Categories: Zany, Cute, Interesting. Cambridge, MA; London, England: Harvard University Press, 2012. 60-62. Print.

Rainer, Yvonne. Feelings are Facts: A Life by Yvonne Rainer. Cambridge, MA; London, England: Massachusetts Institute of Technology, 2006.

Reichert, Kolja. "Where is the Money?" Spike Art Quarterly 40 (Summer 2014). Accessed January 20, 2015. Web.

Simon, Joshua. Neomaterialism. Berlin: Sternberg Press, 2013. 24-32. Print.

Steyerl, Hito. "A Thing Like You and Me." The Wretched of the Screen. e-flux, Inc. Berlin: Sternberg Press, 2012. 46-57. Print. 